\title{
The Application of Discourse Analysis Theory in the College English Reading Teaching
}

\author{
Peng Cui \\ Feixian Branch, Linyi University Feixian, Shandong, China \\ cuipeng2008.ok@163.com
}

Keywords: Discourse; Discourse Analysis; Reading Teaching.

\begin{abstract}
It's urgent to find a way to improve the college students' reading ability for the time being. Discourse analysis is the study of language use above the layer of sentences, in which many points can be used in the current reading teaching to improve the college students' reading ability. This paper explores the current situation in college reading teaching and shows the effectiveness of discourse analysis in terms of the definition of discourse and discourse analysis, the content of discourse analysis and the application used by the discourse analysis theory in the real teaching practice so as to expect a better effect on the improvement of college students' reading ability.
\end{abstract}

\section{Introduction}

As one of basic skills in the English learning, reading is an important means to broaden horizon and acquire knowledge. English reading plays more roles in the English teaching. While at present college students' reading ability is very poor. In the teaching practice, we find that students are often nervous at the reading task and find it difficult to know the reading materials from the general aspect. Sometimes they have little knowledge about the background of reading materials and just only depend on their sense of comprehension when they do the reading tasks. The basic reason is that teachers pay more attention to the teaching of words and grammar and neglect the analysis of the text for the whole point of view. Under this kind of teaching situation, the students may be good at the use of words and sentences in English reading, but they lack the comprehension of reading content. So it is essential to find a way to improve the college students' reading ability for the time being. While Discourse analysis is the study of language use above the layer of sentences, many points of discourse analysis can be used in the current teaching. So the author think it's necessary to apply the discourse analysis theory in the English reading teaching.

\section{The Relevant Theory Concerning Discourse Analysis}

The Definition of Discourse and Discourse Analysis. As a linguistic term, discourse has been given different definitions by scholars. Crystal (1992) believed discourse is the cluster of language that is larger than a sentence, especially the spoken language often constitutes such a coherent unit as a sermon, a speech, a joke or narration. G.W. Huang (1988) thought that discourse is the language unity made up of the series of coherent sentences. Generally, discourse is a functional language unity that has a logic structure, meaningful coherence, cognitive principle and can achieve a certain communicative purpose (Y.L. Duan, X.Y. Kong, 2004). The cohesion and coherence are the two major characteristics in discourse.

As to the discourse analysis, D. Numan (1993) defined it as the functional analysis of discourse, different from the text analysis that emphasizes the characteristics of language system. In short, discourse analysis takes text as the basic unit, analyzing the content of the text form the macro and micro-level, it not only attaches much importance to the linguistic form and functional factors, but also emphasizes the cultural factors and relevant knowledge so as to cultivate the students' ability to comprehend, analyze and get the whole information.

The Content of Discourse Analysis. From the functional point of view, discourse analysis studies the language in communication; it refers to the relationship between language and the context in 
which it exists. The language can be presented in spoken and written form. Specifically speaking, all that be concerned with the language use in communication belongs to the content of discourse analysis. Discourse analysis is a kind of comprehension and analysis of the text from the perspective of unity, and it includes the micro-structure analysis and macro-structure analysis (G. W. Huang, 2001:6). Micro- structure Analysis means identifying the lexical meaning, syntactic structure and the relationship among sentences. And one of its main tasks is to find the cohesive relation which is the surface structure and tangible net in the discourse. It explores how a series of sentences make up a coherent discourse via lexical cohesion, grammatical devices and logical connection. So from the micro-structure perspective, analysis of cohesion, coherence and context are mainly discussed. For the macro-structure analysis, it refers to some common textual patterns which are very useful in the English language teaching, that is problem-solution pattern, claim- counterclaim pattern, general-particular pattern which contribute to the macro-structure analysis of discourse.

Macro-structure Analysis. The discourse cannot be completely decoded if the analysis of discourse just stays at word or sentence level. It refers to the analysis of the discourse from the perspective of unity, structure and organization, etc. We should also emphasize its macro-level in order to get the further meaning of the discourse and the author's true intention.

Some linguists such as Michael Hoey, Michael McCarthy and Ronald Carter make a deep research on this field, they all believe that there are many kinds of textual patterns in English discourse. C.D. Liu (2001)also put forward some common textual patterns which are very useful in the English language teaching, that is problem-solution pattern, claim- counterclaim pattern, general-particular pattern which contribute to the macro-structure analysis of discourse.

Problem- Solution Pattern. The problem-solution pattern can be seen in the scientific thesis, news report, experiment record and literary articles and it is usually made up of situation, problem, response and evaluation or result. This pattern has its own characteristics in the lexical signals, among which such words as problem, solution and result often occur in the English discourse. McCarthy (2002:79) once summed up some lexical signals in each part of discourse. The words such as concern, problem, hamper, difficulty, and dilemma and so on can be found in the problem part. The words such as come up with, find, change and so on are the lexical signals in the response part.

Claim-Counterclaim Pattern. This kind of textual pattern which can also be called Claim-Response Pattern or Hypothetical-Real Pattern usually occurs in the debating, comment, and political discourse. It is usually made up of three parts that is situation, claim and response. In the claim part, the author often states what he said or the other's opinion (sometimes its authentity remains unclear). In the response part, the author gives his own view to what he illustrated in the claim part. Sometimes he or she supports or refuses, agrees or disagrees with what illustrated in the claim part and give the right reason for it.

General-Particular Pattern. General-Particular Pattern or General-Specific Pattern can be seen in the many English discourses. This pattern has two kinds of forms. One is called Generalization-Example, its own characteristic is to generalize the main idea of the discourse first, and then specify it with some examples. The other is Preview-Detail. Its characteristics are to give the outline of the discourse first, and then specify it in detail. McCarthy (cited from $\mathrm{Hu}, 2005$ ) believe that there are two kinds of macro-structure patterns. They are as follows:

A: General statement-Specific statement 1 - Specific statement 2-Specific statement 3 -etc. --- - General statement

B: General statement—Specific statement— Even more specific—Even more specific—etc. ---General statement

Micro-structure Analysis. Micro-structure Analysis means identifying the lexical meaning, syntactic structure and the relationship among sentences. And one of its main tasks is to find the cohesive relation which is the surface structure and tangible net in the discourse. It explores how a series of sentences make up a coherent discourse via lexical cohesion, grammatical devices and logical connection. So from the micro-structure perspective, the main study of discourse includes the analysis of cohesion, coherence and context. Cohesion is the tangible network of discourse (G.W. 
Huang, 1988), and the main content in the discourse analysis. It refers to semantic links among the language components in the discourse.

Cohesion. It is a kind of cohesive effect which is achieved by the choice of words. In most cases, the lexical cohesion occurs when two or more lexical items have the meaningful cohesion. It means to set up a way of sequence through the lexical choice to establish continuity of discourse. Meanwhile, lexical cohesion is the most important and prominent form, constituting the most advanced way of cohesion. Generally, lexical cohesion includes repetition, synonymy, hyponymy and collocation, which make the relationship among sentences correlative and the discourse coherent.

Mostly each cohesive means doesn't come alone. On the contrary, more than one cohesive means can correlate and intertwine with each other and play the important role in the link of sentences. From the micro-structure analysis of discourse, the tangible network lying in words, sentences can be found out by using different types of cohesion mentioned above. In this way, it is helpful for students to conquer the language barrier, get the necessary relations between words and sentences into their head and thus make preparations for the analysis and comprehension of discourse further.

Coherence. It refers to the semantic relevance of the discourse by the manner of logic reasoning. Coherence is the intangible network of discourse (G.W. Huang, 1988) and reflect the deep structure in the discourse. When it comes to coherence, it not only depends on cohesion, but also attaches much importance to the meaning of sentences and the logic sequence in the arrangement of sentences in the discourse. Sometimes it still relies on the prerequisite of conversation, the mutual knowledge shared by the speaker and reader, and sometimes even the readers' association and imagination. Cohesion as a feature of discourse is objective while coherence is subjective and it is the aspect used for evaluating the whole discourse and can be only measured by readers. Meanwhile the coherence of discourse is relative rather than absolute characteristics and it can range from the most consistent to the inconsistent, however, coherence is the most basic feature of discourse.

Context Analysis. It refers to the speech event in a certain time and space, in other words, the situation in which the discourse is involved in the location, time, and characters and so on. Context is the basis and prerequisite for discourse analysis and is interdependent and mutually supplementary with the discourse. It is impossible to throw light on the text interpretation corresponding to the author's intention if the understanding of the context cannot be got correctly .For a written discourse the important contextual factor lies in the reading between the lines. Situations, the speaker and hearer's shared knowledge and experience are also important factors besides the context in a spoken discourse. We believe that written discourse is actually the special form of dialogue and the communicative language between authors and readers. In the process of reading, the situations, shared knowledge and the subjective factors are prerequisites for discourse analysis (C.D. Liu, 1999).

\section{The Application of Discourse Analysis in the College Reading Teaching}

In the reading teaching, the college students can be taught the reading text in each unit with the discourse analysis-based reading method when it came to each reading material: 1) it was necessary to supply students with background knowledge and then asked some questions related to the text to arouse their great interest. In dealing with the reading material, students were asked to find the topic sentence in each paragraph and further found the theme of this reading text. And then let them learn the discourse structure and the connections between paragraphs in this reading material in order to make them have the better understanding of the author's intention at the macro-level. 2) The reading text was taught at the micro-level. Some aspects such as reference, conjunction, lexical cohesion are mainly analyzed. This process also referred to the teaching of some language points, the difference was that they were placed in a certain language context.

A teaching example was given to see how different the teaching model was carried out.

In the class used by discourse analysis theory:

Example: Unit 7 Reading Text One: The History of Movies

Step One Greetings

Step Two Introduction 
During this step, the teacher will do the warm-up activities with students.

Firstly, the teacher will raise two questions which are close to the text or the reality. For example: Do you like movie? Have you seen any English movie?

Secondly, the teacher will let students have small discussion.

For example: Name other kinds of movie. During this period, the teacher would give some pictures in the multimedia to let students guess what kind of movie it belongs to and then the teacher will give his opinions about it.

Step Three. Skimming Reading

During this period, the teacher would ask students to look through the text as quickly as possible and pay close attention to the first or the last paragraph in order to get the general idea the teacher told them. After reading, students can answer the questions as follows: What were the earliest films like? Which year was the best time for American movies? What kind of problems did American movies face in the 1950s?

Step Four. Intensive Reading and Discourse Analysis

In this period, the teacher let students read the text word by word, sentence by sentence in 15 minutes or so, finding some aspects at the macro-structure level, such as the topic sentence in each paragraph, the way sentences are combined and so on. The teacher would check the right answers as follows:

Paragraph One: The origin of movies.

Paragraph Two: The history and the themes of movies.

Paragraph Three: The further development of movies in the modern world.

Secondly, the teacher would guide students to learn some means of cohesion such as ellipsis, conjunction and lexical cohesion and so on in the text. For example,) "Then somebody began saying movies, and soon everybody was."(In para 1) The ellipsis is used by the author, because the words "saying movies" are omitted after the word "was" in the latter part of this sentence. 2) The first all-talking picture was shown, and the development of sound film helped the industry pass safely---(in para 2).Lexical cohesion is adopted because the words "all-talking picture"' and "sound film" have the same meaning in this sentence.3) Conjunction in this text: however, but, as well as, meanwhile, and, then.

Thirdly, let students outline and learn the useful language points in the language context. For example: elevate, distribution, constant, in vain, come into existence, close down, etc.

\section{Conclusion}

As is mentioned above, we can draw a conclusion that discourse analysis can help college students improve their reading ability better than before. Discourse analysis can arouse students' great interest and enhance their self-confidence in the English reading. Students under the traditional teaching model do their reading task passively, they cannot apply what they learned in the reading class, and they lack the ability to organize, to develop the task from the whole perspective at the given time. While students under the method of discourse analysis can overcome these obstacles mentioned above, students can have better understanding of the author's true intention and the skills of how the author developed the text step by step. Meanwhile they can express what's on their mind more actively in the group activity and feel it easier to finish the reading task in time. And their great interest and their confidence in the reading can be stimulated and enhanced.

\section{References}

[1] Crystal, D: Directions in Applied Linguistics (Academic Press, England1981).

[2] Flood, James \& Lapp, Diane: Reading and Writing Relationship: Assumptions and Directions. (Reading and Communication Press, America 1987).

[3] Halliday, M.A.K. \& Hason, R.Cohesion in English. (Longman Press, England 1976) 
[4] Y. L. Duan, X.Y. Kong: Foreign Language and Their Teaching, Vol. 6(2004) No.12, p.78.

[5] G.W. Huang: Theory and Practice of Discourse Analysis-A Study on Advertising Discourse (Foreign English Teaching Press, China 2001).

[6] M. Wang: Schema Theory and English Reading Teaching, Foreign language and Their Teaching, Vol. 11 (2008) No.4, p.52. 